\title{
The Effect of Indentation Angle of Koch Fractal Boundary on the Performance of Microstrip Antenna
}

\author{
P. Nageswara Rao and N. V. S. N. Sarma \\ Department of Electronics and Communication Engineering, National Institute of Technology, Warangal 506004, India
}

Correspondence should be addressed to P. Nageswara Rao, nrraop@yahoo.com

Received 20 November 2007; Revised 27 February 2008; Accepted 16 April 2008

Recommended by Pavel Nikitin

The effect of indentation angle of Koch fractal boundary applied to a triangular patch on the resonant behavior and bandwidth is presented. It is shown that the resonant frequency can be controlled by changing the indentation angle of the boundary. With the experimental verification, it is established that for an indentation angle of $30^{\circ}$ more bandwidth is obtained compared to conventional $60^{\circ}$.

Copyright (C) 2008 P. N. Rao and N. V. S. N. Sarma. This is an open access article distributed under the Creative Commons Attribution License, which permits unrestricted use, distribution, and reproduction in any medium, provided the original work is properly cited.

\section{INTRODUCTION}

It is required to design and fabricate antennas which are compact in size, low profile, conformal, and having multiband characteristics especially in military and commercial applications [1]. There are various techniques available in the literature to design compact antennas like providing shorting pins at regular intervals, or slots on the patch, and so forth. However, the use of fractals to design compact antennas is a recent technique. The fractal antennas are not only of compact size but also operate at multiple bands. Hence, fractal antennas more or less satisfy many of the aforesaid properties. The term fractal means broken or irregular fragments originally introduced by Mandelbrot to describe complex shapes that possess an inherent self-similarity or self-affinity in their geometrical structures. The main idea of using fractal geometries in the design of microstrip antenna is to increase the effective electrical length through which current travels. This is generally referred to as space filling property of fractal and upon which the size reduction of the patch depends.

Conventional approach to the analysis and design of microstrip antennas is to use Euclidean geometry. Since fractal geometry is an extension of classical geometry, its introduction provides antenna designers an opportunity to explore a new and innovative antenna design. There are an infinite number of fractal geometries available, but a few can be applied to microstrip antennas to observe their behavior particularly on the size reduction and multiband operation. Sierpinski carpet and Sierpinski gasket antennas are familiar fractal geometries for their multiband operation $[2,3]$. The Koch curve is one of the most familiar fractal curves which can be used as wire antennas to reduce the size and for multiband operation. The behavior of dipoles using Koch curves of different fractal dimension is presented by Vinoy et al. [4]. Borja and Romeu [5] have presented the behavior of Koch curve fractal boundary microstrip antenna with different iterations in the localized and nonlocalized modes, and they described the behavior of the same as highdirectivity antenna. The effect of varying the indentation depth of Minkowski loop wire antenna on its resonant frequency is presented in [6]. The use of fractal boundary antenna in multistandard terminals like LAN, GSM1800, and UMTS applications is presented in [7]. The Indentation angle used for the boundary by the authors $[5,7]$ is only $60^{\circ}$. To the best of authors' knowledge, the other possible indentation angles are not considered till now to study the resonant behavior and bandwidth especially as boundary for the patch. It is shown that the less complex shapes filling less space is more effective at lowering resonant frequency [8], and optimizing the Koch fractal boundary using genetic algorithm can reduce the size of the antenna up to $55 \%$ 
[9], but they are confined only to wire antennas. When the indentation angle of the fractal boundary applied to triangular patch is changed, very interesting points are observed about the resonant behavior and the bandwidth of the patch. In the present work, the variation of resonant frequency and bandwidth with the indentation angle of Koch fractal boundary is investigated. The experimental results are compared with MoM-based IE3D simulation results.

\section{ANTENNA GEOMETRY}

The proposed fractal boundary microstrip antennas are obtained by replacing each side of triangular patch antenna by Koch curve of varying indentation angles. It is to study the effect of indentation angle of fractal boundary on the resonant frequency and bandwidth of the antenna.

The fractal dimension is one of the important properties of fractals. It is a measure of the space filling ability of a fractal curve. There are different versions of fractal dimensions available in the literature, but the most easily understood definition for the fractal dimension is self- similarity dimension. It is defined as

$$
D=-\frac{\log n}{\log (1 / s)},
$$

where $n=$ number of copies, $s=$ scaling factor.

For the standard Koch curve, indentation angle $(\theta)=$ $60^{\circ}, n=4, s=3$, and $D=1.261$. If the indentation angle is made variable, the scaling factor becomes function of $\theta$ and is given by

$$
\frac{1}{s}=\frac{1}{2(1+\cos \theta)} .
$$

Thus, geometries with varying fractal dimension can be obtained using this generalization. In the present work, the generalized Koch curve is used as boundary for the triangular patch antenna and the behavior is presented in detail. The geometry of the antennas is shown in Figures 1-3.

\section{NUMERICAL RESULTS AND DISCUSSION}

The antennas are analyzed using Zeland IE3D electromagnetic simulator and are printed on RT Duroid substrate having thickness of $3.2 \mathrm{~mm}$ and relative permittivity of 2.33 . All the antennas are fed using probe feed at a position, where input impedance is $50 \mathrm{ohms}$. The return loss characteristics are measured with HP 8719A vector network analyzer. Because of manufacturing constraints, only first three iterations are considered. Hence, these are only prefractals not actually fractals. In this paper, two cases have been considered: one with all the antennas having same initial side length of $49.3 \mathrm{~mm}$ and changing indentation angle and iteration of the boundary. The 2 nd case is to consider the antennas operating at the same frequency changing the indentation angle and iteration.

Case 1. When the indentation angle of the Koch fractal curve applied to the triangular patch as boundary is varied, it is

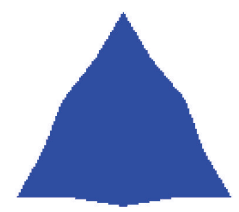

(a)

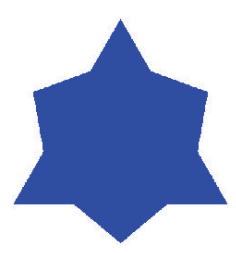

(d)

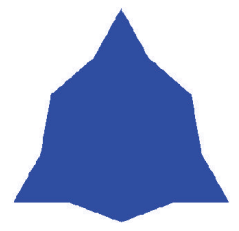

(b)

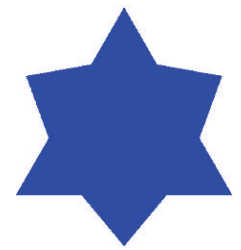

(e)

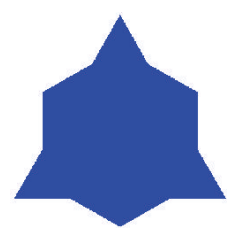

(c)

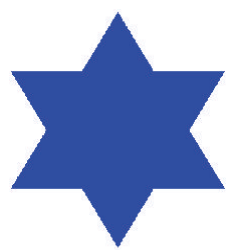

(f)
FIGURE 1: First iterated Koch fractal boundary microstrip antennas with indentation angles (a) $10^{\circ}$, (b) $20^{\circ}$, (c) $30^{\circ}$, (d) $40^{\circ}$, (e) $50^{\circ}$, and (f) $60^{\circ}$.

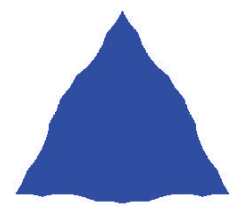

(a)

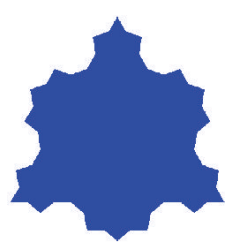

(d)

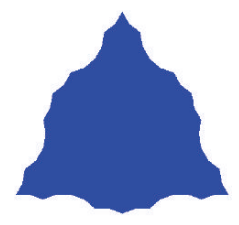

(b)

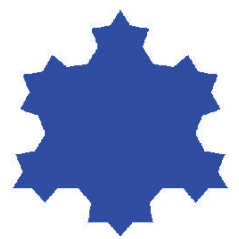

(e)

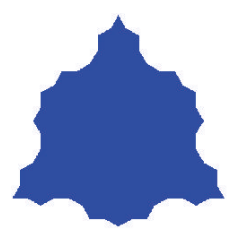

(c)

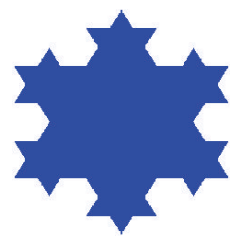

(f)
FIgURE 2: Second iterated Koch fractal boundary microstrip antennas with indentation angles (a) $10^{\circ}$, (b) $20^{\circ}$, (c) $30^{\circ}$, (d) $40^{\circ}$, (e) $50^{\circ}$, and (f) $60^{\circ}$.

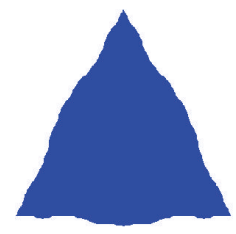

(a)

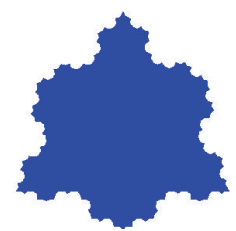

(d)

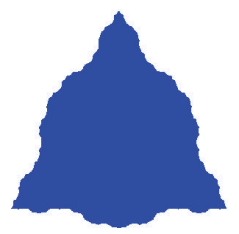

(b)

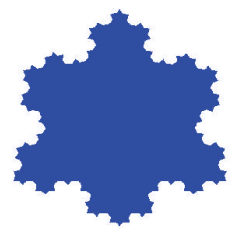

(e)

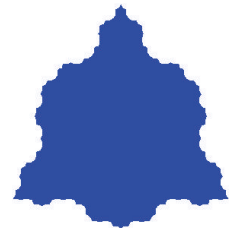

(c)

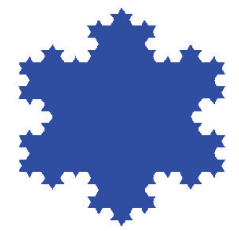

(f)
Figure 3: Third iterated Koch fractal boundary microstrip antennas with indentation angles (a) $10^{\circ}$, (b) $20^{\circ}$, (c) $30^{\circ}$, (d) $40^{\circ}$, (e) $50^{\circ}$, and (f) $60^{\circ}$. 
TABLE 1: Resonant frequency and bandwidth of proposed antennas.

\begin{tabular}{|c|c|c|c|c|c|c|}
\hline \multirow{2}{*}{ Indentation angle } & \multicolumn{2}{|c|}{ 1st iteration } & \multicolumn{2}{|c|}{ 2nd iteration } & \multicolumn{2}{|c|}{ 3rd iteration } \\
\hline & $\mathrm{fr}(\mathrm{MHz})$ & $\mathrm{BW}(\mathrm{MHz})$ & $\mathrm{fr}(\mathrm{MHz})$ & $\mathrm{BW}(\mathrm{MHz})$ & $\mathrm{fr}(\mathrm{MHz})$ & $\mathrm{BW}(\mathrm{MHz})$ \\
\hline 10 & 2492 & 57.2 & 2475 & 55.6 & 2468 & 55.2 \\
\hline 20 & 2488 & 59.2 & 2450 & 57.6 & 2434 & 55.6 \\
\hline 30 & 2474 & 70.2 & 2400 & 58.2 & 2380 & 63 \\
\hline 40 & 2424 & 61.6 & 2327 & 54 & 2264 & 51.6 \\
\hline 50 & 2368 & 59 & 2228 & 49.6 & 2161 & 47.5 \\
\hline 60 & 2311 & 56 & 2116 & 43.2 & 2048 & 39.2 \\
\hline
\end{tabular}

TABLe 2: Percentage reduction of resonant frequency with iteration and indentation angles.

\begin{tabular}{lcccc}
\hline Iteration & fr for indentation angle $10^{\circ}(\mathrm{MHz})$ & fr for indentation angle $60^{\circ}(\mathrm{MHz})$ & Shift $(\mathrm{MHz})$ & $\%$ reduction of fr \\
\hline 1st & 2492 & 2311 & 181 & $7.26 \%$ \\
2nd & 2475 & 2116 & 359 & $14.5 \%$ \\
3rd & 2468 & 2048 & 420 & $17 \%$ \\
\hline
\end{tabular}

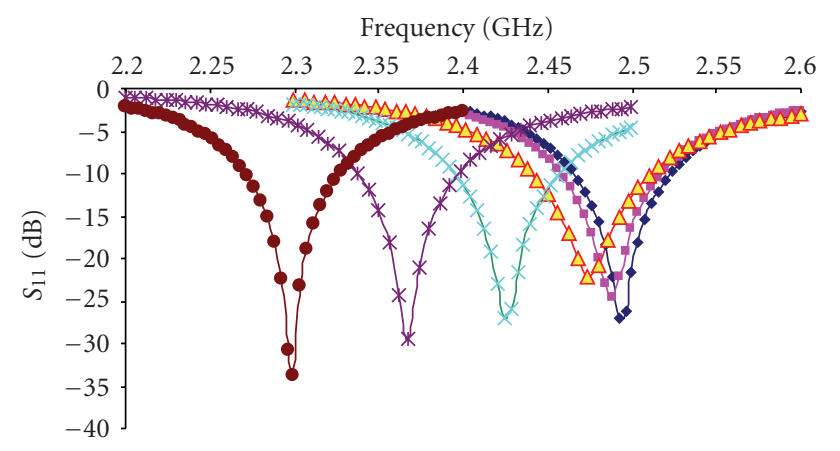

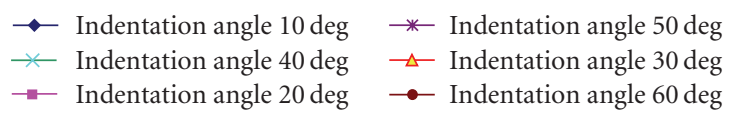

FIgURE 4: $S_{11}$ characteristics of 1 st iteration Koch fractal boundary microstrip antennas with different indentation angles.

observed that the resonant frequency of the antenna can be systematically controlled. The shift in the resonant frequency is observed not only with indentation angle but also with iteration of the fractal boundary as can be observed from Figures 4-6.

From Table 1, it can be inferred that when the indentation angle is changed from $10^{\circ}$ to $60^{\circ}$, the resonant frequency is changed from $2492 \mathrm{MHz}$ to $2311 \mathrm{MHz}$ for the first iterated fractal antenna, where as for the 2nd iterated antenna it is changed from 2475 to $2116 \mathrm{MHz}$, and for 3rd iterated antenna it is changed from 2468 to $2048 \mathrm{MHz}$. All these antennas are circumscribed in a circle of radius $28.4 \mathrm{~mm}$ that is $a / \sqrt{3}$, where " $a$ " is the initial side length of the triangle. The percentage reduction of resonant frequency for different iterations is listed in Table 2.

It is interesting to note an important observation that the bandwidth of these antennas also changes with indentation

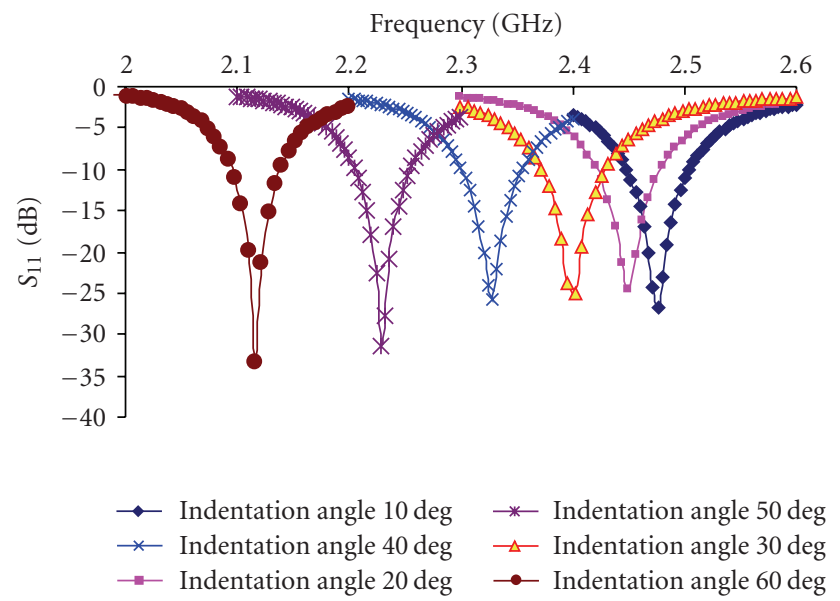

FIGURE 5: $\mathrm{S}_{11}$ characteristics of 2nd iteration Koch fractal boundary microstrip antennas with different indentation angles.

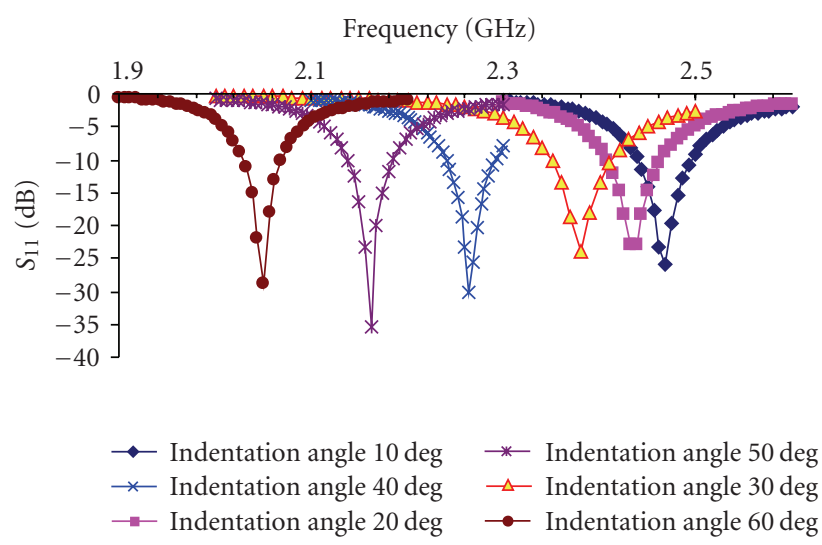

FIGURE 6: $S_{11}$ Characteristics of 3rd iteration Koch fractal boundary microstrip antennas with different indentation angles. 
TABLE 3: Comparison of simulated and measured results.

\begin{tabular}{|c|c|c|c|c|c|}
\hline \multicolumn{2}{|c|}{ Antenna } & \multicolumn{2}{|c|}{ Resonant frequency $(\mathrm{MHz})$} & \multicolumn{2}{|c|}{$10 \mathrm{~dB}$ Imp bandwidth (MHz) } \\
\hline Indentation angle & Iteration & Simulated & Measured & Simulated & Measured \\
\hline $30^{\circ}$ & 1 st & 2474 & 2476 & 70.2 & 82 \\
\hline $30^{\circ}$ & 2nd & 2400 & 2402 & 58.2 & 66 \\
\hline $30^{\circ}$ & $3 r d$ & 2380 & 2386 & 63 & 63 \\
\hline $60^{\circ}$ & 1 st & 2312 & 2298 & 56 & 60 \\
\hline $60^{\circ}$ & $2 \mathrm{nd}$ & 2116 & 2118 & 43 & 47 \\
\hline $60^{\circ}$ & $3 r d$ & 2048 & 2049 & 39 & 42 \\
\hline
\end{tabular}

TABLE 4: Area and perimeters of 1st iterated fractal boundary antenna with different indentation angles $(a=49.3 \mathrm{~mm})$.

\begin{tabular}{lcccc}
\hline Indentation angle & Area $\left(\mathrm{mm}^{2}\right)$ & Perimeter $(\mathrm{mm})$ & Ratio of area to perimeter & BW $(\mathrm{MHz})$ \\
\hline 10 & 1135 & 149 & 7.6 & 7.9 \\
20 & 1216 & 153 & 8.12 & 57.2 \\
30 & 1283 & 158 & 8 & 70.2 \\
40 & 1344 & 167 & 7.7 & 61.6 \\
50 & 1389 & 180 & 7.13 & 59 \\
60 & 1405 & 197 & & 56 \\
\hline
\end{tabular}

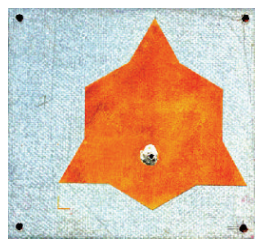

(a)

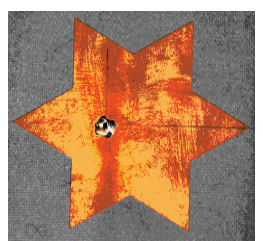

(d)

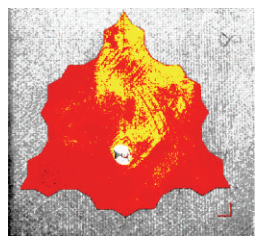

(b)

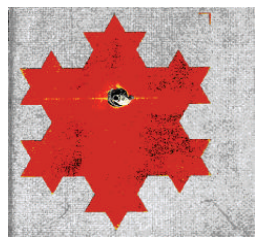

(e)

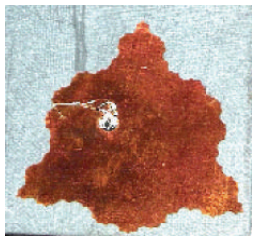

(c)

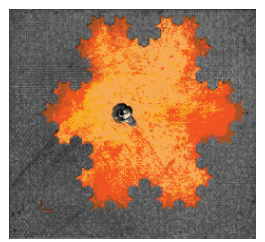

(f)
Figure 7: Fabricated fractal boundary patch antennas with indentation angles of $30^{\circ}$ and $60^{\circ}$ : 1st iteration, 2nd iteration, and 3rd iteration.

angle. For all the three iterations, it is demonstrated that more bandwidth is obtained for fractal boundary antenna with an indentation angle of $30^{\circ}$ compared to the conventional angle of $60^{\circ}$. The higher bandwidth is because of higher value of area to perimeter ratio. The above-simulated values are experimentally verified. The photographs of the antennas are shown in Figure 7.

Figure 8 shows the measured $S_{11}$ characteristics of 1st, 2nd, and 3rd iterated fractal boundary microstrip antennas with indentation angle $30^{\circ}$ and $60^{\circ}$. The comparison between measured and simulated results is shown in Table 3 .

The area and perimeter of generalized fractal boundary microstrip antenna can be calculated using the relation given by (3) for the 1st iterated fractal antenna. As said earlier, the higher bandwidth is because of higher value of area to perimeter ratio. This is verified for a particular case of 1st- iteration fractal boundary antenna by changing indentation angle with initial side length of $49.3 \mathrm{~mm}$ :

$$
\begin{aligned}
\text { Perimeter } & =\frac{12 a}{2(1+\cos \theta)}, \\
\text { Area } & =\frac{\sqrt{3}}{4} a^{2}+3 \frac{a^{2} \sin \theta \cos \theta}{[2(1+\cos \theta)]^{2}},
\end{aligned}
$$

$a=$ initial side length of triangular patch, $\theta=$ indentation angle.

Case 2. The above-mentioned antennas are made to operate at a fixed frequency of $2.5 \mathrm{GHz}$, while varying the indentation angle and iteration. The statement of getting less bandwidth for an indentation angle of $60^{\circ}$ is still valid even for the antennas operating at the same frequency as can be observed from Table 5. For example, the bandwidth of 3rd iterated fractal antenna with indentation angle of $60^{\circ}$ is only $48 \mathrm{MHz}$, whereas it is $72 \mathrm{MHz}$ for $30^{\circ}$, both are operating at the same frequency of $2.5 \mathrm{GHz}$. Hence, the indentation angle of the boundary has significant effect on the performance of antenna in terms of both resonant frequency and bandwidth. As the fractal dimension and indentation angle are related, the resonant frequency and bandwidth of fractal boundary can be controlled by varying the fractal dimension of the boundary.

\section{CONCLUSION}

The variation of resonant frequency and bandwidth with indentation angle for first 3 iterations of Koch fractal boundary microstrip antenna is presented. It is observed that the resonant frequency decreases with change in indentation angle apart from change in the iteration. Further, the bandwidth also changes with indentation angle and hence with fractal dimension of the fractal boundary. It is concluded that 

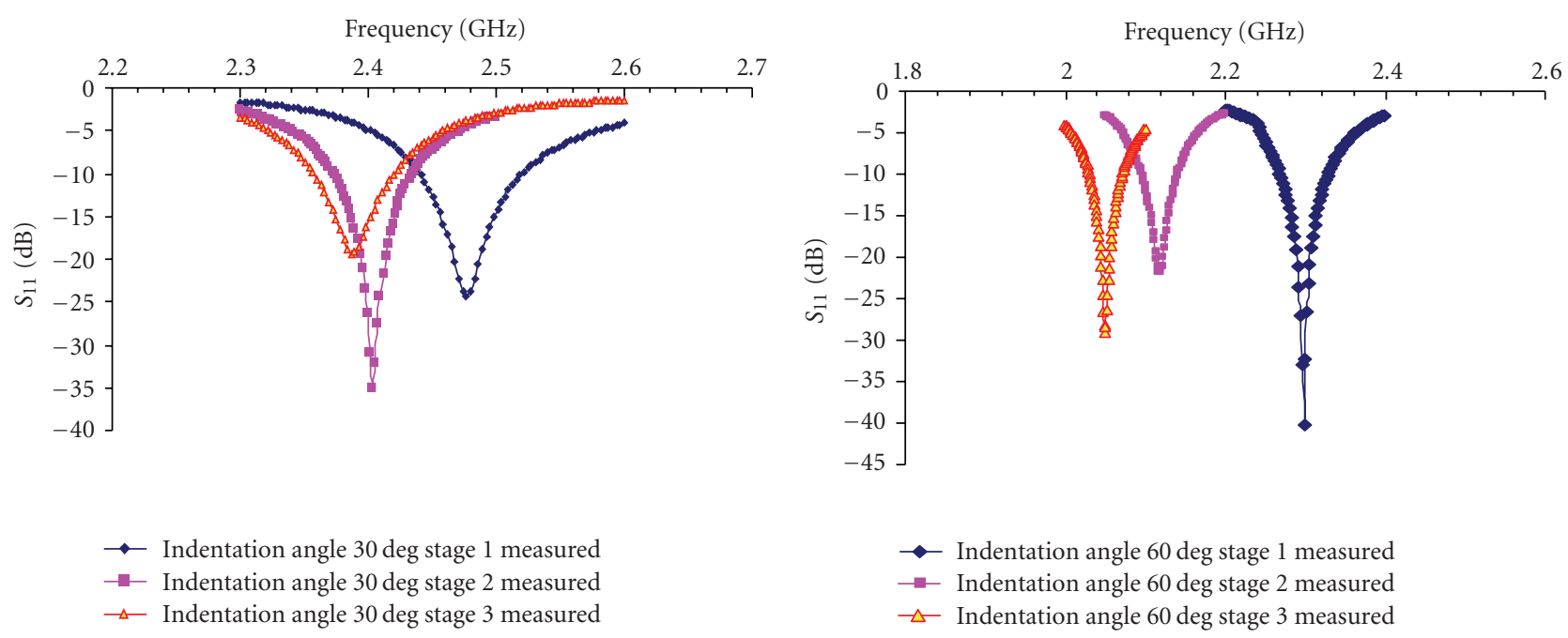

$\rightarrow$ Indentation angle $30 \mathrm{deg}$ stage 1 measured
$\rightarrow-$ Indentation angle $30 \mathrm{deg}$ stage 2 measured
$\rightarrow-$ Indentation angle $30 \mathrm{deg}$ stage 3 measured

(a) (b)

Figure 8: (a) Measured $S_{11}$ characteristics fractal boundary antenna with indentation angle $30^{\circ}$. (b) Measured $S_{11}$ characteristics fractal boundary antenna with indentation angle $60^{\circ}$.

TABLE 5: Bandwidth comparison of antennas operating at the same frequency of $2.5 \mathrm{GHz}$.

\begin{tabular}{|c|c|c|c|}
\hline \multirow{2}{*}{ Indentation angle } & \multicolumn{3}{|c|}{ Bandwidth $(\mathrm{MHz})$} \\
\hline & 1st iteration & 2nd iteration & 3rd iteration \\
\hline 10 & 59 & 52 & 60 \\
\hline 20 & 60 & 67 & 62 \\
\hline 30 & 64 & 70 & 72 \\
\hline 40 & 62 & 67 & 66 \\
\hline 50 & 58 & 64 & 62 \\
\hline 60 & 54 & 56 & 48 \\
\hline
\end{tabular}

better bandwidth can be obtained with different indentation angle than conventional $60^{\circ}$, keeping all the antennas circumscribed within the radius of $a / \sqrt{3}$ (" $a$ " is the initial side length of triangular patch). Hence, the indentation angle can be taken as one of the key parameters for the design of Koch fractal boundary microstrip antennas since all the parameters are being changed with the indentation angle. A very good agreement between simulated and experimental results is obtained.

\section{REFERENCES}

[1] D. H. Werner and S. Ganguly, "An overview of fractal antenna engineering research," IEEE Antennas and Propagation Magazine, vol. 45, no. 1, pp. 38-57, 2003.

[2] C. Puente-Baliarda, J. Romeu, R. Pous, and A. Cardama, "On the behavior of the Sierpinski multiband fractal antenna," IEEE Transactions on Antennas and Propagation, vol. 46, no. 4, pp. 517-524, 1998.

[3] R. V. Hara Prasad, Y. Purushottam, V. C. Misra, and N. Ashok, "Microstrip fractal patch antenna for multiband communication," Electronics Letters, vol. 36, no. 14, pp. 1179-1180, 2000.

[4] K. J. Vinoy, J. K. Abraham, and V. K. Varadan, "On the relationship between fractal dimension and the performance of multiresonant dipole antennas using Koch curves," IEEE Transactions on Antennas and Propagation, vol. 51, no. 9, pp. 2296-2303, 2003.

[5] C. Borja and J. Romeu, "On the behavior of Koch island fractal boundary microstrip patch antenna," IEEE Transactions on Antennas and Propagation, vol. 51, no. 6, pp. 1281-1291, 2003.

[6] J. P. Gianvittorio and Y. Rahmat-Samii, "Fractal antennas: a novel antenna miniaturization technique, and applications," IEEE Antennas and Propagation Magazine, vol. 44, no. 1, pp. 20 36, 2002.

[7] J. Guterman, A. A. Moreira, and C. Peixeiro, "Microstrip fractal antennas for multistandard terminals," IEEE Antennas and Wireless Propagation Letters, vol. 3, no. 1, pp. 351-354, 2004.

[8] D. H. Werner, P. L. Werner, and K. H. Church, "Genetically engineered multiband fractal antennas," Electronics Letters, vol. 37, no. 19, pp. 1150-1151, 2001.

[9] S. R. Best and J. D. Morrow, "The effectiveness of spacefilling fractal geometry in lowering resonant frequency," IEEE Antennas and Wireless Propagation Letters, vol. 1, no. 1, pp. 112$115,2002$. 

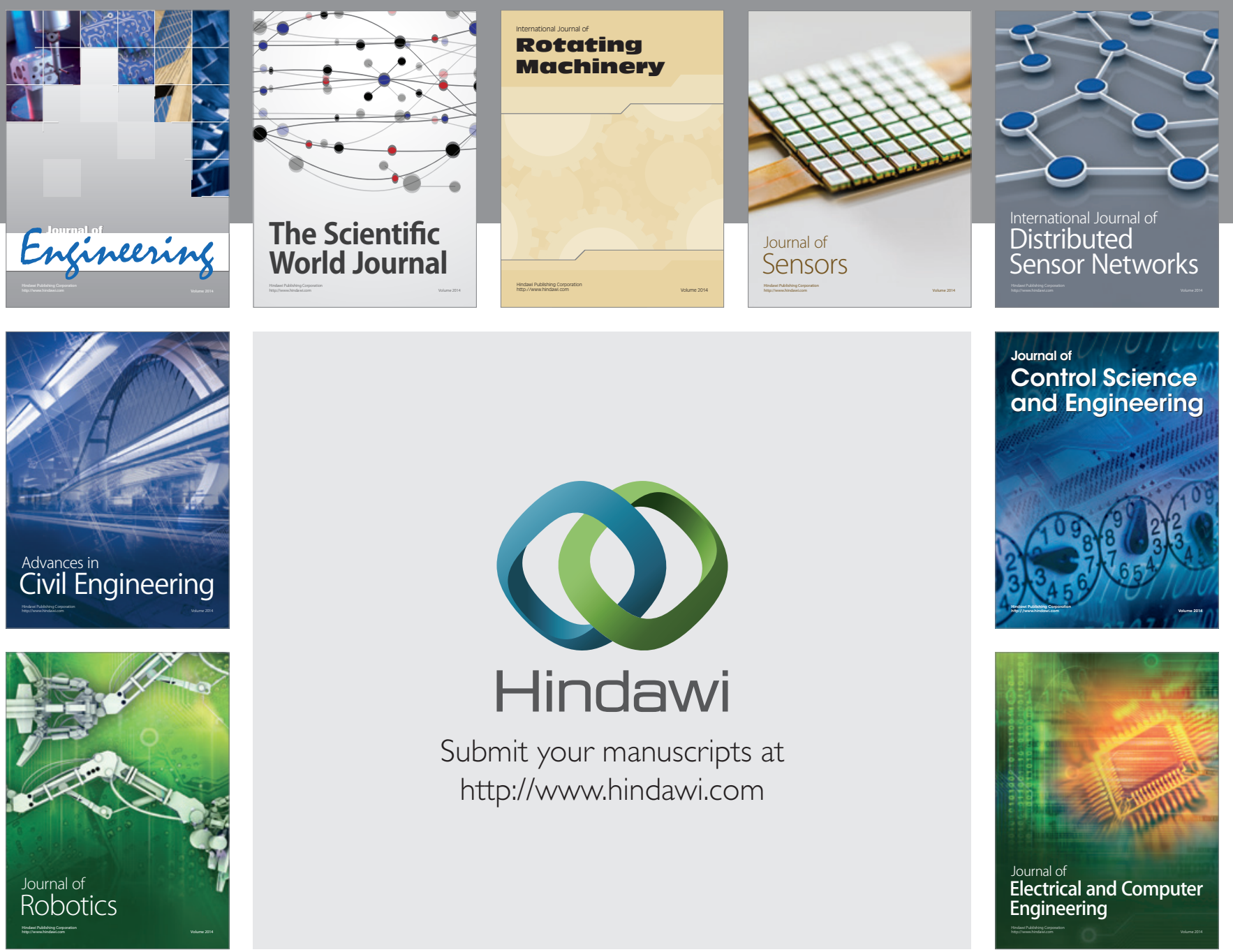

Submit your manuscripts at

http://www.hindawi.com
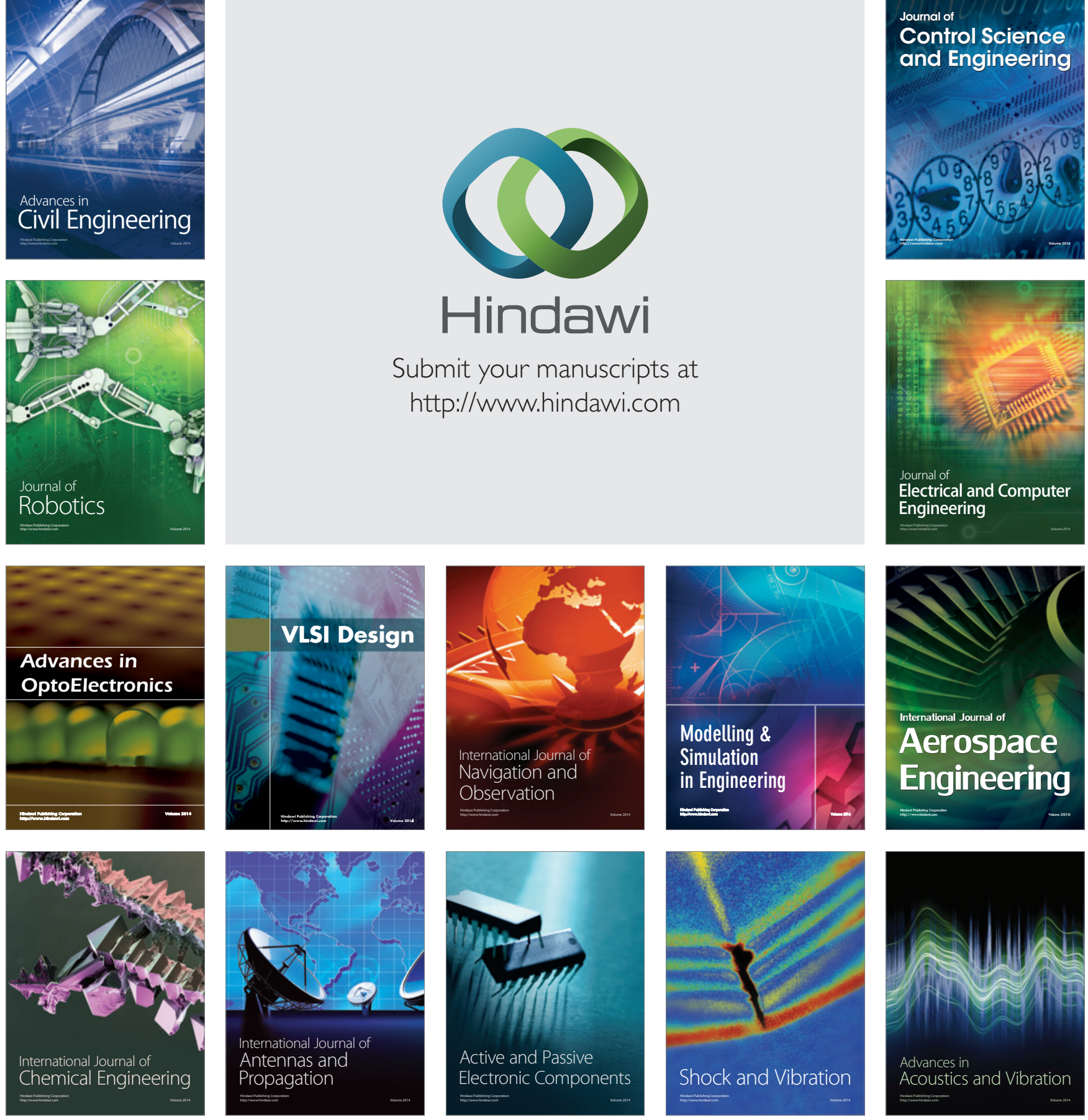